\title{
A Restorative Trail: Restorative Practice - opening up new capacities of hearts and minds in school communities
}

\section{Michelle Stowe}

\begin{abstract}
The aim of the action project outlined in this article was to set up a Professional Learning Community (PLC) in a school with teachers who were interested in inculcating the practices and principles of Restorative Practice in their classrooms. My intention in forming such a PLC was to establish, explore, evaluate and maximise the use of Restorative Practice in participants' classrooms. I wanted to investigate the impact of such engagement on relationships, teaching practices and approaches, and how it could offer a stimulus for whole schoolchange.

Our investigation found that the implementation of Restorative Practice did improve relationships. It promoted empathy and encouraged teachers and students to work together. It developed emotional literacy skills among the participants. Participants gained a sense of ownership over behaviour. There was a change in approach to misbehaviour that had a positive effect on learning and on teachers' feeling of well-being. The evidence shows that improved relationships often had a positive impact on the work ethic within the classroom. Teachers enjoyed working as a solution focused community of teachers, it helped to re- invent and enhance their best practice through the sharing of ideas. The evidence also showed that the implementation and positive impact of Restorative Practice is a process. It is something that requires repeated, structured and reflective engagement, such as that offered by our PLC.
\end{abstract}

\section{Keywords}

Restorative practice, school communities

\section{Aim of this Paper}

This paper begins by offering an introduction and description of the Restorative Practice and a Professional Learning Community. It outlines the aim, focus and purpose of my research and signposts its place in my school and the community it serves. This paper also attempts to broaden an awareness of the implementation of Restorative Practice in schools, offering an insight into understanding the complexities of initiating the necessary paradigm shift needed to re-culture a school community. 


\section{Introduction}

The intention of this action project was to set up a Professional Learning Community (PLC) in my school with teachers who were interested in inculcating the practices and principles of Restorative Practice in theirclassrooms.

\subsection{Restorative Practice}

In broad terms Restorative Practice is a values based philosophy. There are a set of skills and practices that breathe life into this way of being which cultivates, what Belinda Hopkins describes as, a 'restorative mind-set' (Hopkins, 2006: 5). This paradigm shift informs how we think, engage, speak, listen, and approach situations, all day, every day. The intention is to develop a culture of care and respect which is applicable to the whole school community as

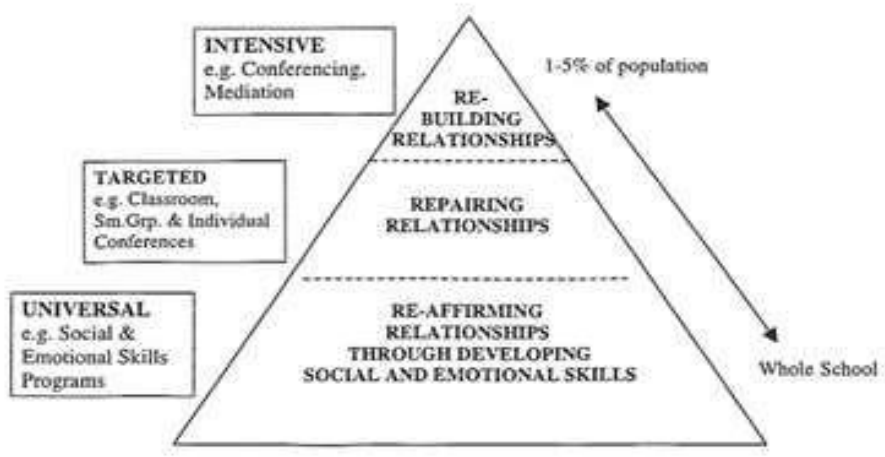
Morrison's (2005: 51)

"Hierarchy of Restorative Responses" pyramid suggests. The proactive element of restorative practice is absolutely essential to build an environment that limits the potential for conflict and its successful resolution if it does occur. It is the carpet that offers foundation, pliability, and warmth to the other reactive strategies. Morrison (2007: 107) draws parallels to the health care 'immunisation' model, whereby the building of positive relationships inoculates communities against conflict.

\section{A Personal Perspective}

My personal definition and experience of Restorative Practice in schools is that it is a collaborative and proactive way of being that aims to build community and manage conflict by modelling positive behaviour. After all, "if we are not modelling what we teach, we are teaching something else" (Hopkins, 2006: 163). It encourages high expectations to be the excellent humans that we were all born to be and offers the support and

\section{RELATIONSHIP WINDOW}

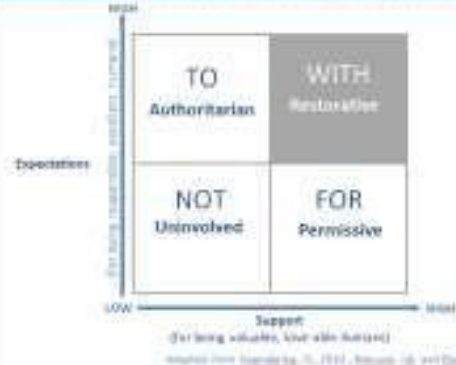
care to meet these expectations as Vaandering's (2010) Relationship Window illustrates. Restorative Practice, when dealing with wrongdoing, facilitates restorative conversations separate the deed from the doer and seeks to understand before being understood (Covey, 2004). It involves a benevolent paradigm shift from punitive to restorative, from blame to connection, from fear to love. "Love is not something that we give or get; it is something that we nurture and grow" (Brown, 2012: 105) and Restorative Practice nourishes such seeds. 
The restorative approach helps us to see in our young students what they may not yet see in themselves. It allows us to offer them a door way into their best selves, a lens from which to see who they really are. For the purpose of this study, and the restorative work I model and promote in my school, that is a worthy and capable student, a valued member of our school community. But for me, on a personal spiritual level, that is a lovely child of God; a beautiful being of light, whose essence is love. Just like Marianne Williamson's (1992) poem 'Our Greatest Fear', (recited by Mandela at his inauguration) reminds us.

\section{Our Greatest Fear}

It is our light not our darkness that most frightens us.

Our deepest fear is not that we are inadequate.

Our deepest fear is that we are powerful beyond measure.

It is our light, not our darkness that most frightens us.

We ask ourselves, 'Who am I to be brilliant, gorgeous, talented, fabulous?'

Actually, who are you not to be?

You are a child of God.

Your playing small does not serve the world.

There is nothing enlightened about shrinking so that other people won't feel insecure around you.

We are all meant to shine, as children do.

We were born to make manifest the glory of God that is within us.

It's not just in some of us; it's in everyone.

And as we let our own light shine, we unconsciously give other people permission to do the same. As we are liberated from our own fear, our presence automatically liberates others.

Restorative Practice is, for me, a 'beauty-full' way to revere, to call forth the very best of who we are, especially when life may have smudged our capacity to reflect it. It empowers people to consciously choose to behave and engage in a way that reflects their true being; so that they are inspired intrinsically by their inner guidance, as opposed to being controlled by the fear of an external punishment or the retribution of a punitive school system. It allows us to have the courage to be vulnerable, to be truly seen, to connect. It powers my purpose, offering me the potential to be the change I want to see $-\mathrm{a}$ world where we live with, from, of, for that our whole hearts because we know, we have remembered, that we are worthy of love and belonging (Brown, 2012). That we are, as Rumi the thirteenth century Sufi poet says, not only a drop in God's ocean, but "God's ocean in one drop." 


\section{A Restorative Mind-Set}

The key to a restorative encounter seems to be what Hopkins (2006) termed "the restorative mind-set" (Hopkins, 2006: 5). This lens allows us to place the harm that has happened in sharp focus rather than merely looking at who is to blame. The intention is to empower those involved to repair the harm. This involves giving them ownership of the problem and its resolution. This contrasts with a more widespread, punitive mind-set of our school systems which often serves to isolate and lock out our students and teachers who are already struggling. It is my belief that, as human beings, we are all doing the best we can base on the way we see the world, our current level of consciousness (Tolle, 2005)' when we know better, we do better'. The use of sanctions and imposing punishment "TO" (Vanderring 2010) students dilutes the opportunity for teachers and students to know and do better. It robs us of the opportunity to grow and make repairs, to consider and express how we feel, and potentially discover a new way to deal with such conflicts in the future.

When considering wrongdoing, Restorative Practice looks through a benevolent lens that transcends blame and instead seeks empathy, connection and solutions. Shame researcher and thought leader Brené Brown (2012) defines blame as the discharge of pain and anger. Her research states that there is, in fact, an inverse relationship between blame and accountability; that blame inhibits connection and blocks our potential to empathise and actuate solutions. Restorative Practice expands its address to crime from merely apportioning blame for the breaking of rules, to a more holistic view; considering wrongdoing as a demonstration of disconnect, to the self and others - a violation against people and relationships (Zehr, 1990).

I am inspired by the traditional indigenous ways such as those of the Babemba Tribe of South Africa who live their restorative values in community, even when, perhaps especially when, someone has caused harm. They gather around them in a circle and remind them of something good they have done; a genuine reason why they like, love or value them, reminding them of their worthiness. They understand that the correction for poor behaviour is not punishment, but love and the remembrance of identity. They believe a teacher is someone who knows their song and sings it to them when they have forgotten it (Boullion, 2009). Restorative Practice allows us to define justice as getting 'well' instead of getting 'even'. As Nelsen et. al (2000) asks, wherever did we get the idea that to make people do better we first have to make them feel worse?

As role models, teachers can demonstrate kindness, compassion, and respect, perhaps especially in times of conflict and challenge. We need to illustrate and teach by example, introduce a new epistemology "a way of being in the world long after the facts have faded from (students') minds" (Palmer,1993, p. 30). As Ginott (1972, p. 5) suggests “(teachers) possess tremendous power to make life miserable or joyous. (We) can be a tool of torture or an instrument of inspiration; (we) can humiliate or humour, hurt or heal. In all situations, it is (our) response that decides whether a crisis is escalated or deescalated, and a person is humanized or de-humanized". A restorative mind-set maximises the potential for us to be conscious of this.

I wanted my research to extend Rumi's kind invitation "out beyond ideas of wrongdoing and 
right doing there is a field. I'll meet you there". To live in community in such a field, where we bring out the best in ourselves and in one another is an intention that inspires me. It is a path I wish to travel and hoped my research would leave a trail towards.

\subsection{Professional Learning Community (PLC)}

A Professional Learning Community (PLC) is a group of people who meet in an organised, structured space that is agenda and solution focused. It promotes supportive relationships, develops shared norms and values, and focuses on the acquisition of knowledge and skills. Teachers collaborate to reinvent practice and share professional growth "sharing and critically interrogating their practice in an on-going, reflective, collaborative, inclusive, learning orientated, growth- promoting way" (Stoll et al., 2006:.223).

The hypothesis is that what "teachers do outside of the classroom can be as important as what they do inside the classroom in affecting school restructuring, teachers' professional development, and student learning" (Seashore et al., 2003: 3). I wanted my action research to incite such a re-culturing and the deep learning that Fullan (2006) proposes they represent; a restorative paradigm shift. Sparks (2002) emphasises that successful learning communities "have at their base high quality relationships, collegiality, reflection, risk taking and collaborative problem solving", all of which would enhance our ability to bring about such a paradigm shift.

\section{A Personal Perspective - Community}

When I think reflectively about what I mean by community, I realise that it is inspired by my spiritual beliefs and value system. Being part of creating community speaks to my own inner truth about who I want to be, as not only a teacher, but as a human being in this world. Similarly, my desire to promote Restorative Practice is, somewhat, connected to my perception of my life's purpose, my personal ideals regarding all of our purpose in this world - to see ourselves in one another (Tolle, 2005). My definition of community, for the purpose of this study, is a group of people who meet in an organised, structured space that is agenda and solution focused - a Professional Learning Community (PLC). But community, on a personal, spiritual level, is a group of individuals who are connected, who share who they are, who see themselves in the other; a group who seeks to serve one another, to promote reflections that offer truthful ways of seeing and being in the world; that offer community. Restorative practices can, in my view, offer the opportunity to achieve this - to understand, to empathise; to become more conscious, connected, and aware. To help us "remember who we are" (Walsch, 1997, p. 21). It also offers the chance to engage and seek our own truth, sometimes, through knowing that of others. Palmer alludes to a need to create such community in education, "a connectedness that honours a spiritual understanding of the hidden wholeness" (Palmer, 1993, xii). I concur. 


\section{Rationale}

My interest in Restorative Practice is driven by its transformative potential; its ability to create caring, respectful communities that I wish to be a part of. My personal vision of an ideal school community is one dedicated to honouring and evolving the relationship between schooling, well-being and happiness (O’Brien, 2008). In my view this can be synthesised through positive relationships, those that Restorative Practice aims to promote. I am inspired by the potential synergy between these and I felt that working in community with fellow teachers in a PLC could help to achieve it.

\subsection{My School Community}

My school was a fertile ground for such restorative seeds to grow in, it has a very strong policy of inclusion and there is a robust pastoral tradition. However, I felt that punitive discipline structures can negate the restorative values enshrined in our school's mission statement. This system may compromise our ability to foster and nurture positive relationships, the scaffolding upon which learning and wellbeing is built (Brooks, 1991). The implementation of Restorative Practice would reflect our school ethos; it could potentially improve attendance and learning; Restorative Practice may develop the life-long emotional literacy skills that are essential for well-being (O’Brien, 2008). This is especially necessary in a school situated in an area of disadvantage where the development of such communication skills may have been hindered due to the problems inherent in such an area.

2.2 Implementation Focus Our school was introduced to Restorative Practice in 2010. Two years later, Restorative Practice was only happening in pockets throughout the school despite the positive feedback from the introduction day and efforts made by myself and fellow champions to increase its profile. We had mainly focused on training senior students in conflict resolution. My reconnaissance showed that a new found focus on teachers was necessary to facilitate the initiation and implementation of Restorative Practice in ourschool.

\section{My Research}

\subsection{Aim of my Research}

The aim of my research was to investigate how Restorative Practice impacted on teacher-student relationships with their chosen challenging class, Class X; and to explore how working as a solutionfocused community of teachers would influence our teaching practices. I would be a facilitator and an active member of this reflective community. I wanted to investigate if there was a significant improvement in class relationships. I felt that if this occurred it would help teachers and our school community to validate the positive impact that Restorative Practice could have. This could foster a commitment to create the Restorative School that I wanted to be a member of. I wanted my action to create a heart-felt and informed choice to commit to a whole school restorative culture; to begin the transition necessary for a restorative paradigm shift. 


\subsection{Research Questions}

My intention in forming such a PLC was to establish, explore, evaluate and extend the use of Restorative Practice in our classrooms. I wanted to investigate the following:

To what extent does such engagement impact on teachers' relationship with their students?

1. To what extent have teacher-student relationships improved as a result of initiating Restorative Practice?

2. To what extent does continual and purposeful collaboration with the principles and practices of Restorative Practice impact on the individual teachers' approach to teaching?

3. To what extent can the work of this small group of teachers provide a stimulus for wider school change towards the principles and practices of Restorative Practice?

\subsection{Methodology}

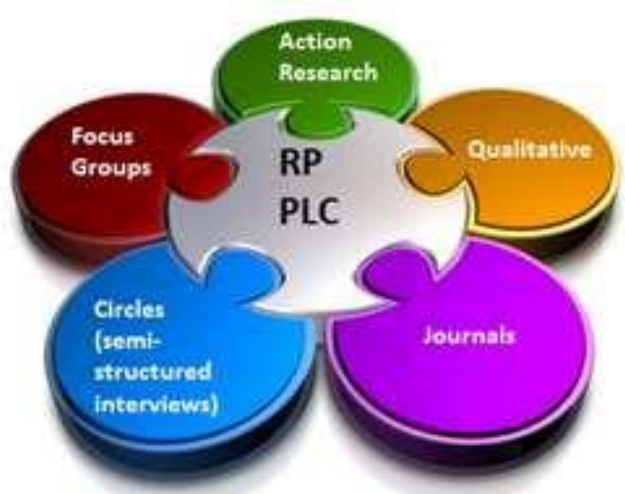

My action research strategy involved twelve actions, many of which evolved iteratively over two cycles over six months. My investigation, in the broadest sense, is interpretive. I am interested in the thought, experiences and feelings of the participants in the study as they implement and consider how Restorative Practice has affected their classroom teaching and relationships. Seeking to gain insight

into educationalists' own experience also roots my research in a constructivist approach, emphasising the importance of working towards a shared construction (a restorative school) which can provide the basis for action in the future (implementation/institutionalisation plan) while co- constructing meaning through experiences, anecdotes and dialogue (assisting a restorative paradigm shift). The research methods of journals, focus groups and restorative circles (semi-structured group interviews) served this qualitative research approach. Weekly circles would not only provide information but promote community in our PLC and model the practices that I hoped participants would use in their classrooms. Journals promoted the necessary reflexivity to assist a paradigm shift and the focus groups allowed for the probing and teasing out of research questions.

\subsection{Findings}

As I do not have enough time to outline all the findings of my research here, I have chosen to illustrate the content of the qualitative data through a series of quotes from the eight teachers (T1 to T8) that snapshot a brief insight into my research questions: 
1.

To what extent does such engagement impact teachers' relationship with their students?
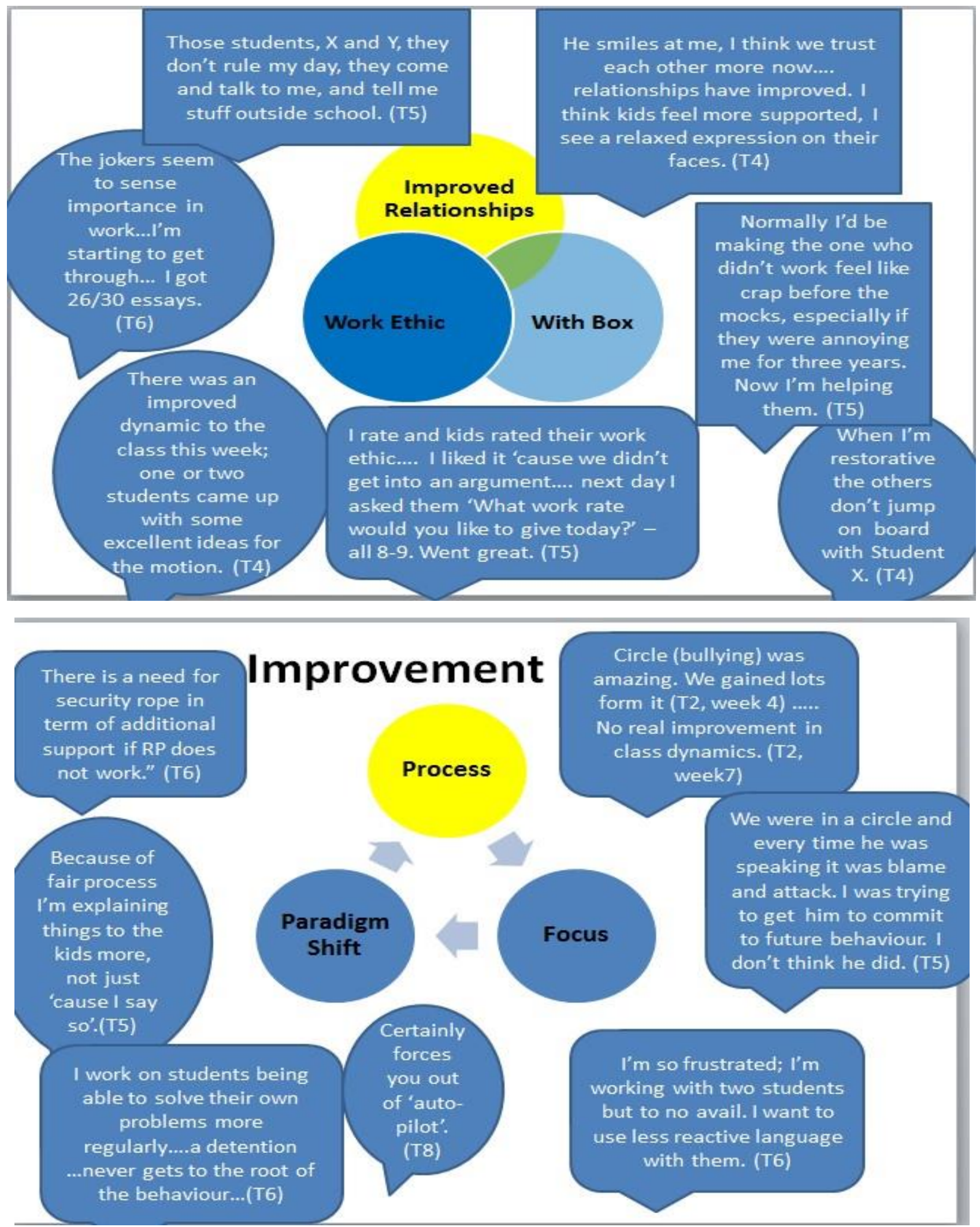
2. To what extent have teacher-student relationships improved as a result of initiating Restorative Practice? $(*$ ELS = Emotional Literacy Skills)

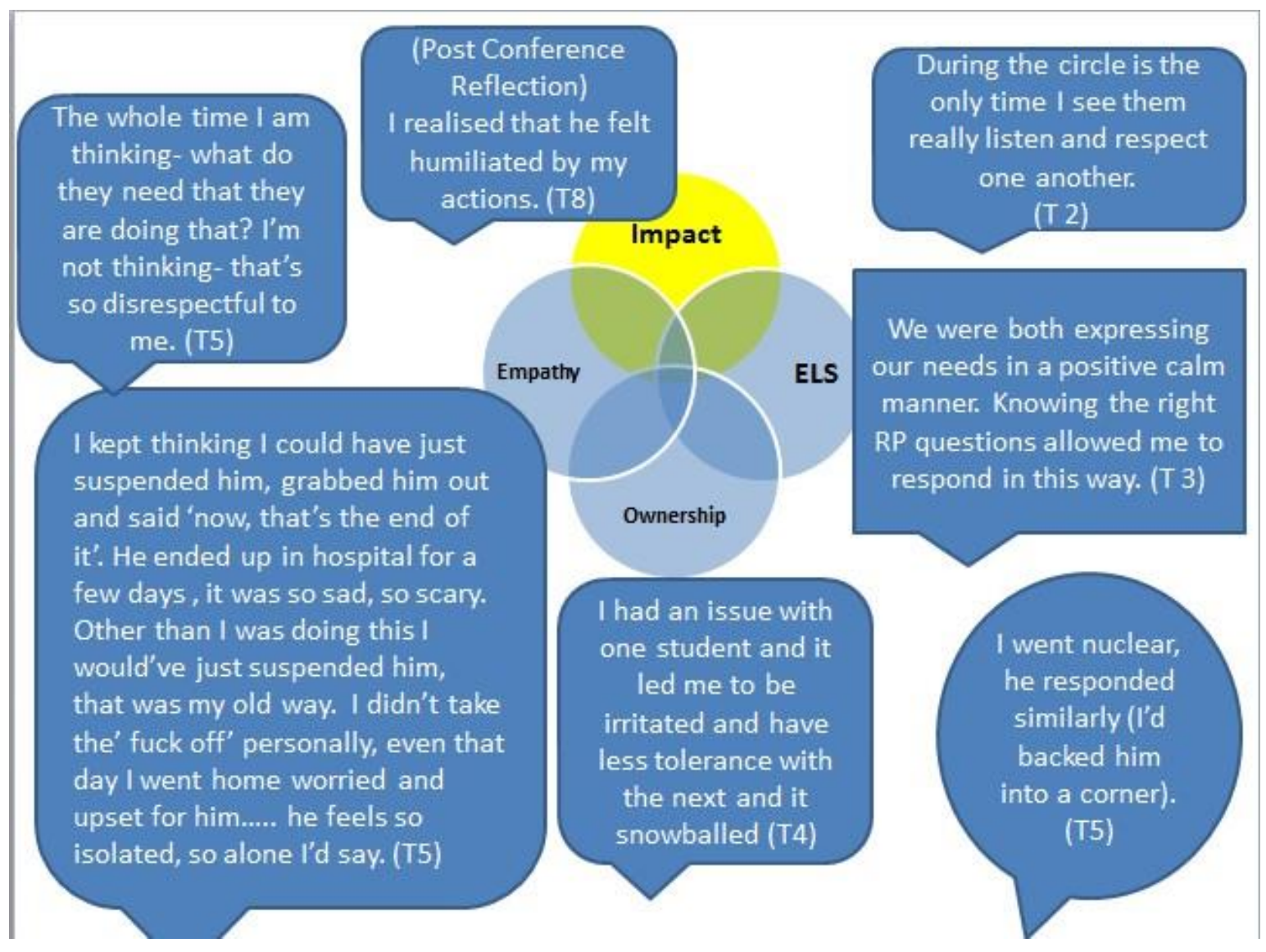


3. To what extent does continual and purposeful collaboration with the principles and practices of Restorative Practice impact on the individual teachers' approach to teaching?

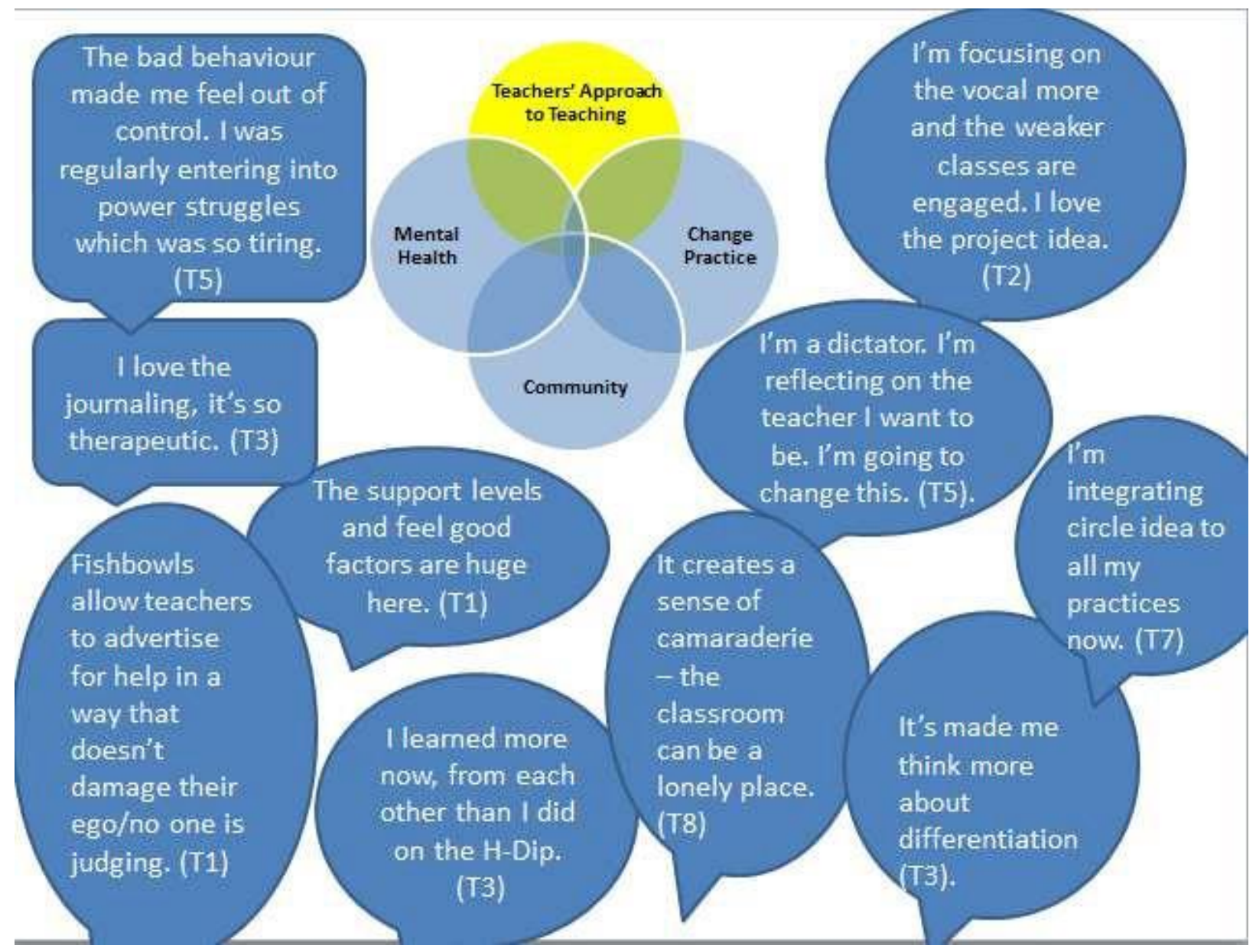


4. To what extent can the work of this small group of teachers provide a stimulus for wider school change towards the principles and practices of Restorative Practice?

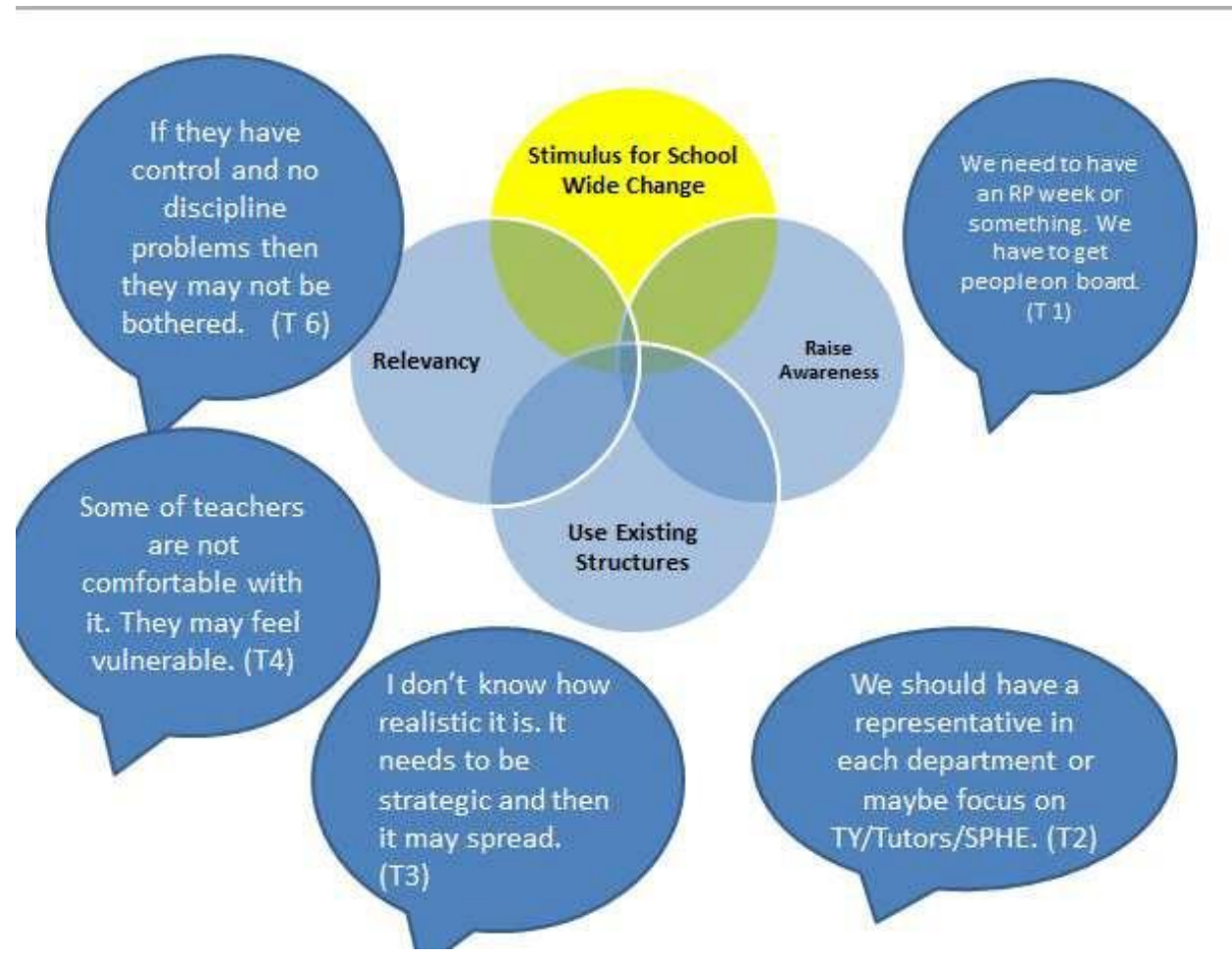

In summary, our investigation found that the inculcation of Restorative Practice did improve relationships. It promoted empathy and developed emotional literacy skills among the participants. Weekly journaling, circles and the use of Restorative Practice in the classroom increased reflection. This, in turn, offered participants a sense of ownership over behaviour. There was a change in approach to misbehaviour that had a positive effect on teachers' mental health and feeling of well-being. The evidence shows that improved relationships often had a positive impact on work ethic within the classroom. Teachers enjoyed working as a solution focused community, it helped to re-invent and enhance their best practice through the sharing of ideas. The evidence also showed that the implementation and positive impact of Restorative Practice is process. It is something that requires repeated, structured and reflective engagement, such as that offered by our PLC. Our PLC could and has had an impact on whole school change which also involves a restorative paradigm shift. This would be a long-term goal, one that the participants of my study and I are committed to. 


\section{Conclusion}

My engagement with Restorative Practice has been an insightful journey that I am still voyaging. For me, it is a way of being in the world, "a compass- not a map... a journey more than a destination." (Zehr, H., 2002: 10). The endeavour of action research has given me a direction with which to utilise this compass in order to find a way that, not only speaks to my core beliefs as a teacher, but echoes my values as a human being.

The opportunity presented to me through this action research has involved me in a community of individuals from whom I have learned much. I feel that it has been a wonderful opportunity for growth and reflection for us all, one that we have committed to evolve and nurture in the future. I am thankful for, not only what we have achieved, but for the potential of its future.

The vision I had in my heart about establishing a community that would make my school a happier place has remained the same throughout my investigation. The 'how' of such an achievement has evolved from a passive knowledge of Restorative Practice that promotes positive relationships to an active awareness of human behaviour that breathes empathy and a benevolent mind-set. The hope that we continue to get to know our true selves and see this in one another inspires me.

.... Don't go where the path may lead

Go instead where there is no path and leave a trail

What lies before you and what lies behind you?

Are small matters compared to what lies within?

And when you bring what is within, out into the world

Miracles happen....

(Ralph Waldo Emerson)

Working in community in our PLC allowed us to voyage an unfamiliar path and leave a trail - opening up new capacities of hearts and minds. These are the miracles I'm grateful for. 


\section{References}

Boullion, J., (2009) Leadership and Love in Action

http://leadingethically.blogspot.ie/2009/09/leadership-and-love-in-action.html $\left(\right.$. acccessed $27^{\text {th }}$

September 2016)

Brooks, R. (1991) The Self Esteem Teacher. Loveland, OH: Treehaus Communication

Brown, B. (2012). Daring Greatly, How the courage to Be Vulnerable Transform the Way We Live, Love, Parent and

Lead. Great Britain by Clays Ltd

Covey, S., (2004) The 7 Habits of Highly Effective People. Great Britain. Simon \& Schuster UK Ltd

Fullan, M. (2006a) Leading Professional Learning, The School Administrator Nov 2006

http://www.michaelfullan.com/Articles_06/Articles_06b.pdf (acccessed online January 2012)

Fullan, M. (2006b) The Future of Educational Change: System Thinkers in Action. Journal of Educational

Change 7(3), 113-122

Ginott, H. G. (1972) Teacher and child: A book for parents and teachers. New York: Macmillan

Golding, D. (1995) Emotional intelligence. New York: Bantam Hopkins, B. (2004) Just Schools. London:

Jessica Kingsley Publishers

Hopkins, B. (2006) Implementing a restorative approach to behaviour and relationship management in schools - the narrated experiences of educationalists

Morrison (2005) Restorative justice in schools. In E. Elliott \& R. M. Gordon (Eds.), New Directions in Restorative Justice (pp. 26-52). Cullompton, Devon: Willan Publishing

Nelsen J., Lott L., \& Glenn S., (2000) Building Classroom Discipline: Positive Discipline in the Classroom. San

Diego State University. Boston

O’Brien, M. (2008) Well-being and post-primary schooling NCCA: Dublin

Palmer, J. P. (1993) To Know As We Are Known - Education as a Spiritual Journey. New York.

HarperCollins

Palmer, J. P. (2000) Let Your life Speak. San Francisco. Jossey-Bass.

Palmer, J. P. (2007) The Courage to Teach Guide for Reflection and Renewal.San Francisco,Wiley

Seashore, K.R., Anderson, A.R. \& Riedel, E. (2003). Implementing arts for academic achievement: The impact of mental models, professional community and interdisciplinary teaming. Paper presented at the Seventeenth

Conference of the International Congress for School Effectiveness and Improvement, Rotterdam, January 2003

Sparks, D (2002) Designing Powerful professional Development for Teachers and Principals National Staff Development Council, USA

Stoll, L., Bolam, R., McMahon, A., Wallace, M., \& Thomas, S. (2006) Professional Learning Communities:

A Review of the Literature. Journal of Educational Change. 10 (7), 221-258

Tolle, E. (2005) A New Earth. England. Clays Ltd

Vaandering, D. (2010) A Window on Relationships : Enlarging the Social Discipline Window for a

Broader Perspective. Presented at 13th World Conference of the International Institute for Restorative 


\section{Practices}

Walsch, D. N. (1997) Conversations with God. Great Britain. Hodder and Stoughton Williamson, M. (1992) A Return to Love. New York. HarperCollins Publishers

Zehr, H. (1990) Changing Lenses. Scottdale, PA: Herald Press

Michelle Stowe is a teacher, restorative practice practitioner, trainer \&consultant interested in promoting positive relationships, happiness \& well-being in the workplace. She has been an active champion of Restorative Practice in her post primary school since becoming an accredited trainer in 2010. She completed her Master's in Education in 2012 and her action research project involved creating a Professional Learning Community to lead the implementation of Restorative Practice in her school community. She is passionate about cultivating a restorative paradigm shift and re-culturing school communities - opening up new capacities of hearts and minds. She is currently on career break from St. mark's Community School, working part-time in the Education Department of Maynooth University, lecturing and supporting the Post Masters in Education students; and as a restorative trainer/consultant, while writing her book on the implementation of Restorative Practices in schools. Restorative Practice allows her to be the change she wants to see in the world, one where we live in community and see ourselves in one another. 